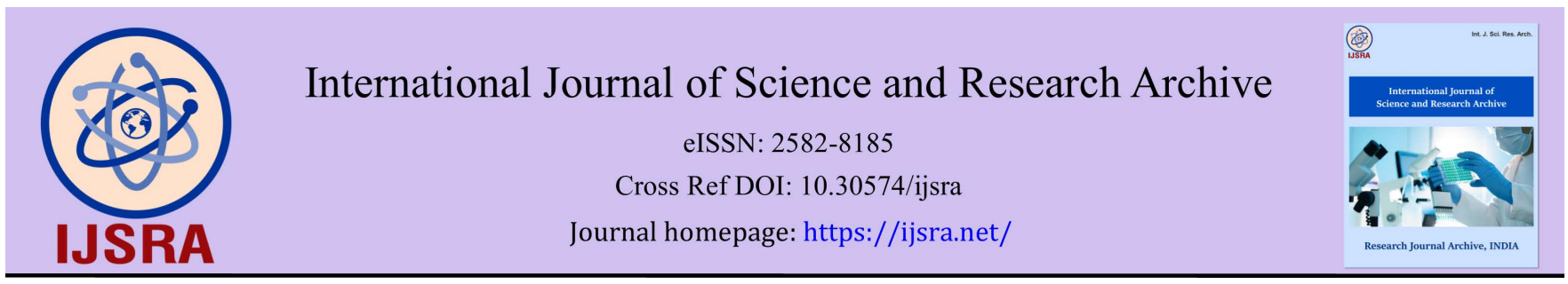

(RESEARCH ARTICLE)

\title{
The study of employment location and transportation accessibility in the Huntsville Metropolitan area
}

\author{
Fola Ayokanmbi ${ }^{1}$, Rolandrea Russell ${ }^{2}$ and Jacob Oluwoye ${ }^{2, *}$ \\ ${ }^{1}$ System and Material Engineering Program Alabama A\&M University, Normal, AL 35762, USA. \\ ${ }^{2}$ Department of Community and Regional Planning, College of Agricultural, Life and Natural Sciences Alabama A \& M \\ University, Normal, AL 35762, USA.
}

International Journal of Science and Research Archive, 2021, 02(02), 183-193

Publication history: Received on 09 April 2021; revised on 19 May 2021; accepted on 22 May 2021

Article DOI: https://doi.org/10.30574/ijsra.2021.2.2.0068

\begin{abstract}
The main purpose of a transportation system is to connect people to their communities and specifically to connect employees to jobs. The Huntsville Metropolitan region's transportation system is without a doubt almost exclusively automobile dependent due to the limited availability of public transportation along with the Regions' 2000 and 2010 Metropolitan Planning Organization (MPOs). Journey to work report. In an automobile dependent region, the level of car ownership is crucial in determining accessibility as well as the ability to utilize employment opportunities. Increased job decentralization and suburban employment throughout various metropolitan areas across the United States decreases the level of employment accessibility resulting in the need for efficient accessibility to the existing transportation system and employment opportunities. Employment accessibility is an issue of great concern in urban areas across the United States significantly in major metropolitans, which is evident based on the continued study, evaluation, analysis, and scrutiny by numerous scholars. In evaluating employment accessibility, the concept of automobile dependency is a relevant factor for the presence of spatial and/or modal mismatch. The purpose of this paper therefore is to examine the relationship between transportation accessibility and employment location in the metropolitan area of Huntsville, Alabama. In doing this the author examines the attributes of residential location, car ownership, house value and other demographic factors of the Huntsville, Metropolitan region to answer the research question of "what, if any is the relationship between these attributes and factors?" Data was obtained from the US Census Bureau for the 2000 and 2010 periods and was extracted then exported and saved as an SPSS document where it was manipulated and analyzed. The Pearson Product Moment correlation coefficients ( $r$ ) were calculated to give an indication of the suggested relationships between variables as the author assesses the employment accessibility in the Huntsville Metropolitan Region. The number of vehicles available which reflects the level of car ownership within the sample is positively related to the residential location indicating that one's residential location is indeed related to owning a car. This paper concludes that spatial mismatch encompasses the economic restructuring of the Huntsville Metropolitan Region's whereby employment opportunities are located far away from areas of residence. Modal mismatch is due to the challenges and/or inabilities faced by individuals in their travels between home and work or place of potential employment.
\end{abstract}

Keywords: Employment; Residential; Location; Transportation; Accessibility; House value; Car ownerships

\section{Introduction}

The ability to commute from one desired place to another is a luxury shared by virtually the entire population of the $21^{\text {st }}$ century throughout the United States [1]. Changes in land use have encouraged the continued development and

\footnotetext{
${ }^{*}$ Corresponding author: Jacob Oluwoye

Department of Community and Regional Planning, College of Agricultural, Life and Natural Sciences Alabama A\&M University, Normal, AL 35762, USA.
}

Copyright $(2021$ Author(s) retain the copyright of this article. This article is published under the terms of the Creative Commons Attribution Liscense 4.0. 
implementation of transportation systems and policies in an effort to adequately cater to individuals' desire and/or need to travel [1] One such need is the commute to employment, which has become crucial component of transportation as a result of increased and continued spatial mismatch influenced by suburbanization and decentralization [2]. The past several decades of job decentralization has posed serious job access problems for America's inner-city poor. Separation from suburban employment, called the "spatial mismatch" problem by some has been blamed for joblessness and concentrated poverty [3] Public transit is not always up to the task of connecting central-city residents to suburban jobs because reverse-commute services tend to be sparse or non-existent [1]. Suburbanization and decentralization are influenced by a number of different push and pull factors. Push factors comprise the congestion and population density of cities, pollution caused by industry, high levels of traffic, and a general perception of a lower quality of life in inner city areas [4]. While the pull factors include more open spaces and a perception of being closer to "nature", lower suburban house prices and property taxes in comparison to the city, and the increasing number of job opportunities in the suburban areas [4]. Furthermore, Handy (1993) [5] presents the argument that the ideal design of a suburban and decentralized area is to reduce the amount of time residents spend in their automobiles. However, loosely populated areas experience the opposite spending more time in their automobiles as well as limiting their level of accessibility.

Commonly the main purpose of a transportation system is to connect people to their communities specifically to connect employee to jobs [1]. The Huntsville Metropolitan region's transportation system is without a doubt almost exclusively automobile dependent due to the limited availability of public transportation along with the Regions' 2000 and 2010 MPOs Journey to work report. In an automobile dependent region, the level of car ownership is crucial in determining accessibility as well as the ability to utilize employment opportunities. Increased job decentralization and suburban employment throughout various metropolitan areas across the United States decreases the level of employment accessibility resulting in the need for efficient accessibility to the existing transportation system and employment opportunities [1] and [6]. The Huntsville Metropolitan Region as a budding economic and cultural mecca within North Alabama requires efficient employment accessibility to all its residents.

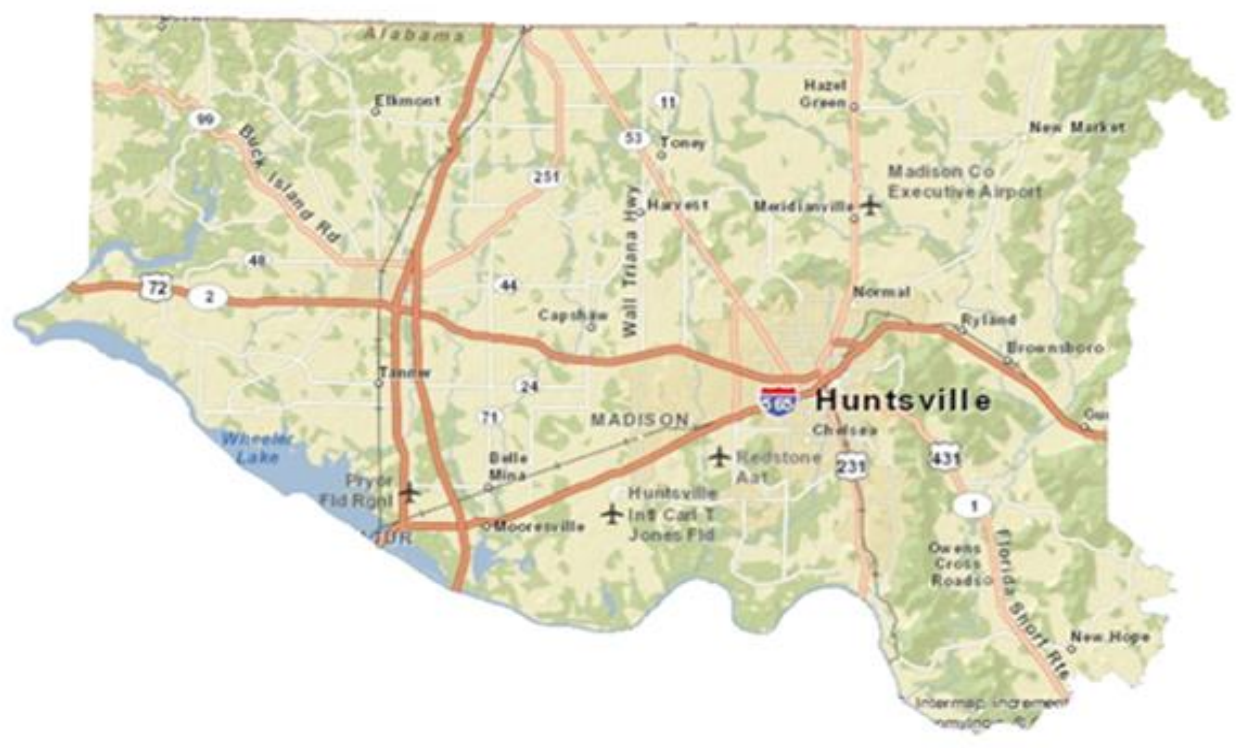

Figure 1 Map of the Huntsville Metropolitan Region highlighting the major roadways

Transportation systems play a pivotal role in accessibility to employment and employment opportunities. Accessibility is defined a number of ways both in the operational and theoretical contexts in an effort to ensure that the results of its measures can be easily understood by policy makers and researchers [7]. The relationship between accessibility, transportation systems and employment has been continually scrutinized by researchers from various perspectives for decades. The purpose of this paper is to examine the relationship between transportation accessibility and employment location in the metropolitan area of Huntsville, Alabama as one of the fastest growing cities in the United States in order to gauge the level of accessibility with its existing transportation system. In doing this the author examines the attributes of residential location, car ownership, house value and other demographic factors of the Huntsville, Metropolitan region to answer the research question of "what, if any is the relationship between these attributes and factors?" Upon determining whether or not a relationship is present between these factors the author's objective is to examine the relationships (if any) between the three sorting variables (percent working in the Central Business District (CBD), 
household car ownership and median house value) and accessibility in an effort to understand the paradigm of employment accessibility in the Huntsville Metropolitan Region.

\section{Literature Review}

\subsection{Accessibility}

Quotes a number [1] of definitions of accessibility such as [8] definition-potential of opportunities for interaction and [9]-the ease of reaching places. Grengs (2010) [1] implies that an accessibility-based perspective should be the focus of planning and policies - one that recognizes that land use patterns influence the ultimate goal of transportation: helping people interact more easily with one another in different locations. Cervero (2005) [2] indicates that accessibility - as an indicator of the ability to efficiently reach oft-visited places - has gained increasing attention as a complement to the more traditional mobility-based measures of performance in transportation planning, such as 'average delays' and 'levels of service'. He indicates that accessibility is a product of mobility and proximity, enhanced by either increasing the speed of getting between point A and point B (mobility), or by bringing points A and B closer together (proximity), or some combination thereof. He also argues that evaluating performance from an accessibility perspective provides a balanced, "more holistic approach to transportation analysis and planning and [most notable that this] gives attention to alternative strategies for reducing traffic congestion and mitigating environmental problems, such as promoting efficient, resource-conserving land-use arrangements" [2].

Relevant to this study is spatial and modal/transportation mismatch-two concepts that significantly impact accessibility. The spatial mismatch hypothesis is a product of the 1968 John Kain study. [1] explains the spatial mismatch hypothesis as the concentration of "...poverty among African Americans in central cities as a result of dispersing jobs that places a growing share of metropolitan jobs in distant suburbs, racial discrimination in housing that confines racial minorities to the urban core, and inadequate transportation that offers poor linkage between the central city and suburbs." Kain's hypothesis has continually been challenged since its inception based on the lack of regard for the mode/means of transportation choosing focus solely on the physical location of employment/Central Business District [1] Nevertheless, modal/transportation mismatch is a byproduct of one's inability to travel to the desired destination in a reasonable amount of time [1]. The ability to travel to destinations in a reasonable amount of time is dependent on the use of either public or private means of transit. Breube et al (2011) [10] presents the menacing phenomenon in which 30 percent of jobs within the top 100 largest US Metropolitan areas are accessible by public transit within 90 minutes. Public transit primarily serves the urban areas despite continued suburbanization indicating that along with the lengthy commute between destinations there is a logistical problem with the transportation system that negatively impacts accessibility [9]. Despite the differences in definitions and factors of accessibility, scholars presents the conscientious that ease of access is not only influenced one's spatial location but also the means of transportation available.

\subsection{Residential location}

As the American society we live in has evolved we have seen in the early stages of development the majority of the population moving to cities in search of employment then later moving to the outskirts to raise their families significantly after World War II. Some of these cities later became the current metropolitans with the outskirts turning into some of the more popular suburbs. With the reversal of residential location came the movement of employment opportunities to the suburbs limiting the accessibility of employment to people residing in metropolitan areas. This prompts the question of how/whether people living in the suburbs outside these CBD areas have access to transportation systems in close proximity to their residences which will take them from their residence to the respective CBDs.

Metropolitan areas typically have fairly efficient public transit systems, some of which do not service the automobile dependent suburbs where a number of employment opportunities are now located, creating a modal and spatial mismatch [11] The modal and spatial mismatch is due to the challenges/inabilities faced by individuals in their travels between home and work or place of potential work. Gordon et al (1989) [12] stated that larger cities with higher population densities suggests shorter trips to work while low density cities tend to produce longer trips. Areas within close proximity to the CBD are more prone to have a high population resulting in the commuting time for people residing in these areas being shorter than those who live further away usually the suburbs [12]. CBDs are also now being moved to the suburbs away from the core of metropolitan areas and densely populated areas. 


\subsection{House value}

House value, when it comes to accessibility, tends to vary depending on the residential location. The further away one's house is from the CBD or transit facility within a metropolitan region, the lower its value typically is, with buyers willing to pay more to live near transit centers or major access roads. One's house value is also determined by the neighborhood's characteristics and demographical make up. In an effort to determine how accessibility affects house value researchers use the hedonic price model which, despite the varying results, implies that the majority of housing values increase as accessibility improves [13]. Furthermore, Jackson (1979) [13] reported that several studies have produced contradicting results regarding the impact of the relationship between housing prices and accessibility. In an effort to formulate a general means of measuring the relationship between housing prices and accessibility in which the traditional hedonic regression model and power series were compared in an effort to adequately measure accessibility in regard to varying housing prices using the city of Milwaukee.

The hedonic regression model is a method of estimating demand or value. It decomposes the item being researched into its constituent characteristics, and obtains estimates of the contributory value of each characteristic. This includes characteristics such as the number of bedrooms, size of lot, or distance to the city center. The hedonic regression equation treats these attributes separately, and estimates prices or elasticity for each of them. The power series commonly referred to as trend surface analysis which is a technique extensively used in geology [13]. Trend surface analysis is a method based on low-order polynomials of spatial coordinates for estimating a regular grid of points from scattered observations delineating the spatial location of houses based on their monetary value in relation to CBDs. The comparison of the hedonic regression model and the power series resulted in the double power series being successful in presenting accessibility along with the discrepancies of traditional accessibility measures.

\subsection{Car ownership}

Car ownership is possibly one of the most effective tools for decreasing unemployment among families in poverty. As mentioned above, public transit has its limitations in connecting low-income individuals with jobs, prompting the implication that owning your own car has a positive impact on the accessibility to employment. Car ownership for lowincome individuals may aid in the accessibility to employment; however, it also adds to the individual's expenses in the form of maintenance and insurance costs. Fan (2012) [14] reported that low-income households have lower car ownership rates and a higher reliance on public transit when compared to higher earning income households. People with access to only public transit therefore could face a significant amount of limited mobility based on proximity in which they reside from public transportation, their place of work and the reliability of their public transportation system.

The ownership of one's mode of transportation is desired by practically everyone in an auto dependent environment, from low to high income brackets in order to maximize their travelling utility and comfort from the point of origin to their destination. Yi's (2009) [11] study stated that owning a car would help low-income individuals retain jobs, providing the flexible mobility required to undertake more than one specific shift during a day, compared to having to transfer by transit several times [11]. Furthermore, Yi (2009) [11] observed that 76 percent of individuals with less than $\$ 20,000$ annual household income in urban areas; 79 percent of African Americans and more than 80 percent of Hispanics; used private vehicles as their major mode of transportation. These statistics show that despite the availability of public transit low-income and minority individuals prefer to satisfy their transportation needs by owning a car which guarantees the privacy and flexibility to work any available shift off.

Grengs (2010) [1] confirms that people who live in neighborhoods further away from the major centers of employment/CBDs are not disadvantaged by their location, but by the disproportionate number without cars in an environment designed exclusively for cars. However, "motor vehicle ownership is now almost universal in the United States" [10]. Car ownership has steadily increased over the decades making this mode of transportation the preferred choice. Owning a car provides commuters with convenience, comfort and schedule flexibility not afforded to those who do not, substantially increasing the accessibility indices for automobile travel opposed to travel by transit [1]. Owning a car is critical in connecting with suburban jobs [1]. Yi (2009) [11] states that since 2001 over 90 percent of all work and shopping related commutes across the United States is carried out using automobiles, indicating how crucial car ownership is to the concept of accessibility.

\section{Methodology}

The sample area of the Huntsville Metropolitan Region assessed in this study was broken down to the census tract level. A total of ten (10) census tracts were selected including census tract 31 which is identified by the Huntsville's zoning ordinance as the Central Business District. 


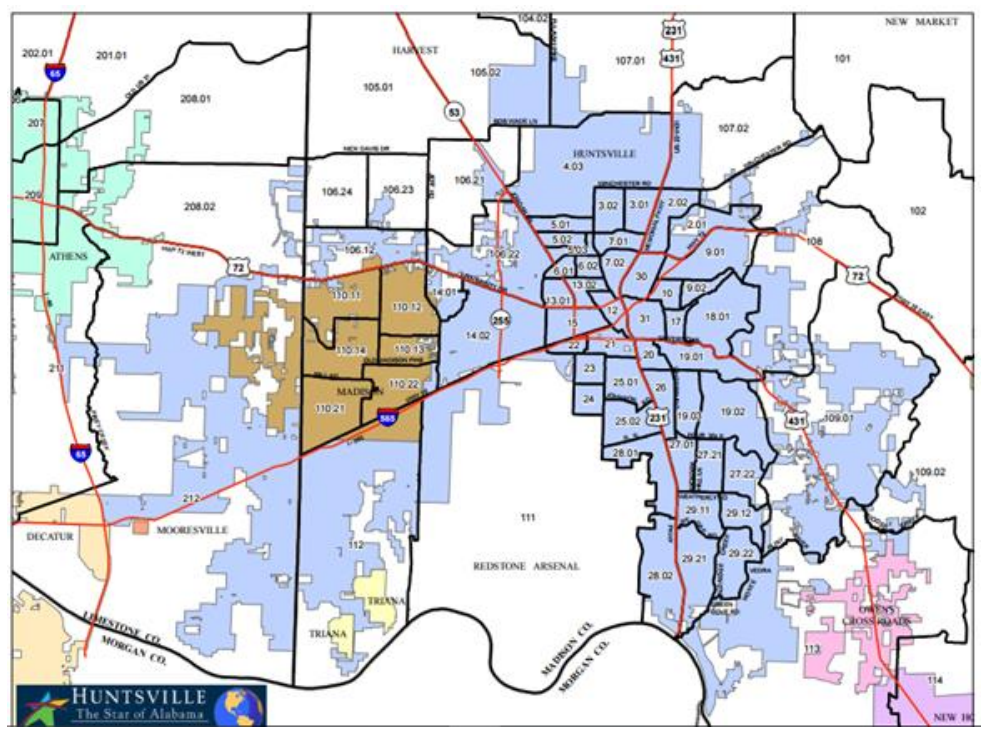

Figure 2 Map of Huntsville Census Tracts

A quantitative analysis was utilized to explore the variables of residential location, car ownership and median housing value with the intention of identifying the factors that impact on the accessibility to employment. This method was also used to assess the connection between the selected variables and accessibility. Data on Huntsville was obtained from the US Census Bureau for the 2000 and 2010 periods. Variables included the population of the selected sample, household car ownership, and median house value, in order to enable the examination of whether or not there is a relationship between the said variables and accessibility. To determine and subsequently examine whether or not there is a relationship between the mentioned variables and accessibility a correlation analysis will be carried out using Huntsville's census data from 2000 and 2010. This correlation analysis is to establish the relationships between and among the variables being studied, recognizing the trends and patterns of collected data. Data was extracted from the Census Bureau's website, then exported and saved as an SPSS document where it was manipulated and analyzed. A Regression analysis was used to determine the relationship if any, between the variables and accessibility.

\section{Results}

\subsection{Data Analysis}

As an automobile dependent region, it is evident that the level of car ownership is a major factor in accessing employment in the Huntsville Metropolitan Area. Huntsville's Metropolitan Organization (MPO) in its 2010 Journey to Work report indicates that approximately $77 \%$ of the metropolitan's population drove to work alone, indicating a high percentage of car ownership throughout the Metropolitan Region. Based on data from the US Census it is calculated that car ownership increased by $53.8 \%$ in 2010 from the previous decade (2000). A lack of car ownership means that residents within the study area have to employ other means of transportation to commute to work. Despite the presence of other means of transportation within the metropolitan area, as expected, the majority, 95\% of commuters use automobiles to commute to work. Of that 95\%, approximately $86 \%$ drive alone, with $11.6 \%$ carpooling and mere $0.37 \%$ commuting by public transportation in 2000 . These statistics clearly indicates that even though the majority of the study area's population commuted using automobiles or chose to drive alone the remainder of the population was able to employ other modes/methods to commute. The level of people who commute by automobile, based on the stated statistics in the region being studied, limits the prospects of spatial and transportation mismatch typically experienced by other metropolitan regions with lower automobile ridership numbers. This level of residents commuting by automobile is typically a reflection of a community's economic status which is strongly related to income and/or residential location. [15] theorized in "Traditional Neighborhoods and Auto Ownership" that the rate of car ownership oftentimes does influence how people choose their residential location.

Huntsville City's transportation system consists of a fixed route bus system which serves selected routes in the Huntsville area along with an on-demand service known as Handi-Ride. Upon its inception in 1990 the Huntsville shuttle bus system consisted of only two routes; the Red and Blue Core loops which serviced Downtown, the Medical District and surrounding areas. The shuttle has since expanded to a total of nine (9) and two (2) weekend routes that services Downtown and its immediate vicinities. The limited availability of public transit in the metropolitan region emphasizes 
the importance of car ownership along with how automobile dependent the studied populace is, highlighting the transportation mismatch experienced by residents that do not have access to their own automobile.

Table 1 illustrates the minimum, maximum, mean and standard deviation of the 16 variables listed for the 2000 period. The sample mean for the aggregate number of vehicles available (car ownership) is 1659.70 with a standard deviation of 405.93. Residential location represented by the variable housing units exhibited a sample mean of 1350.80 with a standard deviation of 377.96. The sample's median household income mean was $\$ 26,705.80$ with a standard deviation of $\$ 14,274.05$. The standard deviation of these important variables reflected the varying levels of car ownership, residential location and income across the metropolitan region in 2000.

Table 12000 Variable mean and standard deviation for sample

\begin{tabular}{|l|l|l|l|l|l|}
\hline Variables & $\mathbf{N}$ & Minimum & Maximum & Mean & Std. Deviation \\
\hline Population & 10 & 1746 & 3531.00 & 2684.2000 & 689.72117 \\
\hline \% Blacks & 10 & .60 & 91.90 & 38.3900 & 29.95554 \\
\hline \% Whites & 10 & 6.00 & 97.50 & 58.7600 & 29.71424 \\
\hline $\begin{array}{l}\text { Aggregate Number of } \\
\text { Vehicles Available }\end{array}$ & 10 & 1181.00 & 2580.00 & 1659.7000 & 405.93816 \\
\hline Vehicles Available (0) & 10 & 42 & 485.00 & 214.3000 & 165.18680 \\
\hline Vehicles Available (1) & 10 & 266 & 855.00 & 515.2000 & 186.62726 \\
\hline Vehicles Available (2) & 10 & 149 & 540.00 & 326.4000 & 106.16361 \\
\hline $\begin{array}{l}\text { Vehicles Available (3 or } \\
\text { more) }\end{array}$ & 10 & 85 & 217.00 & 157.0000 & 49.35360 \\
\hline $\begin{array}{l}\text { Median House Value (in } \\
\text { dollars) }\end{array}$ & 10 & 37000 & 228400.00 & 85181.900 & 60075.17493 \\
\hline $\begin{array}{l}\text { Residential location } \\
\text { (Housing Units) }\end{array}$ & 10 & 903 & 1972.00 & 1350.8000 & 377.96349 \\
\hline $\begin{array}{l}\text { Median Household } \\
\text { Income (in dollars) }\end{array}$ & 10 & 11209 & 58333.00 & 26705.800 & 14273.05562 \\
\hline Average Household Size & 10 & 1.28 & 2.55 & 2.0770 & .37128 \\
\hline $\begin{array}{l}\text { Median Number of } \\
\text { Rooms }\end{array}$ & 10 & 2.80 & 6.90 & 5.0000 & 1.13822 \\
\hline Single-family detached & 10 & 349 & 1485 & 809.7000 & 321.05868 \\
\hline Median Age & 10 & 24.10 & 43.10 & 36.7000 & 5.80957 \\
\hline $\begin{array}{l}\text { Average Commute to } \\
\text { Work (in minutes) }\end{array}$ & 10 & 11.80 & 21.10 & 16.7300 & 2.97174 \\
\hline Valid N (list wise) & 10 & & & & \\
\hline
\end{tabular}

Table 2 like table 1, shows varying levels of the highlighted variables in 2010. The 2010 sample mean for aggregate number of vehicles available was 1669.80 with a standard deviation of 354.76. Residential location had a mean of 1371.40 and a standard deviation of 372.86 and the median household income sample mean was calculated at $\$ 35$, 152.30 with a standard deviation of $\$ 19168.82$.

Comparing both periods based on the sample's mean indicates an increase in the level of car ownership, residential location and the median income from 2000 to 2010. Collectively each variable illustrated some level of growth from 2000 to 2010, even the average commute time increased as well with the presence of more available cars and residential locations. 
Table 22010 Variable mean and standard deviation for sample

\begin{tabular}{|l|l|l|l|l|l|}
\hline & $\mathbf{N}$ & Minimum & Maximum & Mean & Std. Deviation \\
\hline Population & 10 & 1844.00 & 3495.00 & 2627.8000 & 631.89377 \\
\hline \% Blacks & 10 & .80 & 86.40 & 40.0200 & 30.05690 \\
\hline \% Whites & 10 & 6.90 & 96.00 & 54.3300 & 30.97009 \\
\hline Vehicles Available & 10 & 1250.00 & 2515.00 & 1660.8000 & 354.75995 \\
\hline Vehicles Available (0) & 10 & 26.00 & 421.00 & 185.5000 & 147.95363 \\
\hline Vehicles Available (1) & 10 & 328.00 & 835.00 & 502.1000 & 172.39583 \\
\hline Vehicles Available (2) & 10 & 179.00 & 502.00 & 348.0000 & 95.32168 \\
\hline $\begin{array}{l}\text { Vehicles Available } \\
\text { (3 or more) }\end{array}$ & 10 & 48.00 & 215.00 & 140.6000 & 52.70716 \\
\hline $\begin{array}{l}\text { Median House Value } \\
\text { (in dollars) }\end{array}$ & 10 & 48700.00 & 396000.00 & 141260.00 & 114127.48427 \\
\hline $\begin{array}{l}\text { Residential location } \\
\text { (Housing Units) }\end{array}$ & 10 & 899.00 & 2015.00 & 1371.4000 & 372.85928 \\
\hline $\begin{array}{l}\text { Median Household } \\
\text { Income (in dollars) }\end{array}$ & 10 & 11261.00 & 77679.00 & 35152.300 & 19168.81728 \\
\hline Average Household Size & 10 & 1.78 & 2.57 & 2.1130 & .25016 \\
\hline Median Number of Rooms & 10 & 4.30 & 7.10 & 5.3100 & .86980 \\
\hline Single-family detached & 10 & 573.00 & 1368.00 & 866.1000 & 236.84334 \\
\hline Median Age & 10 & 25.50 & 47.80 & 38.4700 & 6.38924 \\
\hline $\begin{array}{l}\text { Average Commute to Work } \\
\text { (in minutes) }\end{array}$ & 10 & 13.00 & 20.40 & 15.5600 & 2.28045 \\
\hline Valid N (list wise) & 10 & & & & \\
\hline
\end{tabular}

\subsection{Correlation Analysis}

The Pearson Product Moment correlation coefficients ( $r$ ) were calculated to give an indication of the whether or not there are relationships between the selected variables of Huntsville Metropolitan Region. Tables 3 and 4 below illustrate the relationship between car ownership, house value, residential location, household income and commute time.

Table 3 above is a correlation matrix which demonstrates the relationship between car ownership, house value, residential location, median household income and commute time within the study's sample. The matrix presents a mixture of negative and positive outputs along with indicating both strong and weak relationships across the sample using these selected variables in 2000. The number of vehicles available which reflects the level of car ownership within the sample is positively related to the residential location indicating that one's residential location is indeed related to owning a car specifically in such an automobile dependent environment. Even though this positive relationship between car ownership and residential location, the relationship between these variables and the average commute time to work though positively related, is very weak. Median household income, however, is poorly related to each of the other variables across the sample. Median household income on the other hand demonstrates a highly inverse relationship to zero cars being available for households within the sample, expressing that as household incomes within the sample increased, the likelihood of not owning a car decreases emphasizing the automobile dependency of the Huntsville Metropolitan Region resulting in the inference that owning a car is in fact a means of necessity instead of choice across the region. 
Table 3 Year 2000 Census Tracts: Pearson Correlations Matrix

\begin{tabular}{|c|c|c|c|c|c|c|c|c|c|}
\hline & $\begin{array}{l}\text { Aggregate } \\
\text { number of } \\
\text { vehicles } \\
\text { available }\end{array}$ & $\begin{array}{l}\text { Vehicles } \\
\text { available } \\
(0)\end{array}$ & $\begin{array}{l}\text { Vehicles } \\
\text { available } \\
\text { (1) }\end{array}$ & $\begin{array}{l}\text { Vehicles } \\
\text { available } \\
\text { (2) }\end{array}$ & $\begin{array}{l}\text { Vehicles } \\
\text { available ( } 3 \\
\text { or more) }\end{array}$ & $\begin{array}{l}\text { Median } \\
\text { house } \\
\text { value }\end{array}$ & $\begin{array}{l}\text { Residential } \\
\text { Location } \\
\text { Housing units }\end{array}$ & $\begin{array}{l}\text { Median } \\
\text { Household } \\
\text { income in } \\
\text { dollars }\end{array}$ & $\begin{array}{l}\text { Average } \\
\text { commute to } \\
\text { work in } \\
\text { minutes }\end{array}$ \\
\hline $\begin{array}{l}\text { Aggregate number of } \\
\text { vehicles available }\end{array}$ & 1 & -0.133 & 0.690 & 0.801 & 0.394 & 0.091 & 0.628 & 0.147 & 0.127 \\
\hline Vehicles available (0) & -0.133 & 1 & 0.391 & -0.291 & -0.560 & -0.154 & 0.564 & -0.739 & 0.175 \\
\hline Vehicles available (1) & 0.690 & 0.391 & 1 & 0.405 & -0.101 & -0.278 & 0.931 & -0.402 & 0.080 \\
\hline Vehicles available (2) & 0.801 & -0.291 & 0.405 & 1 & 0.146 & 0.325 & 0.421 & 0.306 & -0.030 \\
\hline $\begin{array}{l}\text { Vehicles available ( } 3 \\
\text { or more) }\end{array}$ & 0.394 & -0.560 & -0.101 & 0.146 & 1 & 0.044 & -0.249 & 0.363 & 0.039 \\
\hline Median house value & 0.091 & -0.154 & -0.278 & 0.325 & 0.044 & 1 & -0.194 & 0.437 & -0.268 \\
\hline $\begin{array}{l}\text { Residential Location } \\
\text { Housing units }\end{array}$ & 0.628 & 0.564 & 0.931 & 0.421 & -0.249 & -0.194 & 1 & -0.486 & 0.185 \\
\hline $\begin{array}{l}\text { Median Household } \\
\text { income in dollars }\end{array}$ & 0.147 & -0.739 & -0.402 & 0.306 & 0.363 & 0.437 & -0.486 & 1 & -0.095 \\
\hline $\begin{array}{l}\text { Average commute to } \\
\text { work in minutes }\end{array}$ & 0.127 & 0.175 & 0.080 & -0.030 & 0.039 & -0.268 & 0.185 & -0.095 & 1 \\
\hline
\end{tabular}


Table 4 Year 2010 Census Tracts: Pearson Correlations Matrix

\begin{tabular}{|c|c|c|c|c|c|c|c|c|c|}
\hline & $\begin{array}{l}\text { Aggregate } \\
\text { number of } \\
\text { vehicles } \\
\text { available }\end{array}$ & $\begin{array}{l}\text { Vehicles } \\
\text { available } \\
\text { (0) }\end{array}$ & $\begin{array}{l}\text { Vehicles } \\
\text { available (1) }\end{array}$ & $\begin{array}{l}\text { Vehicles } \\
\text { available } \\
\text { (2) }\end{array}$ & $\begin{array}{l}\text { Vehicles } \\
\text { available } \\
\text { ( } 3 \text { or more) }\end{array}$ & $\begin{array}{l}\text { Median } \\
\text { house } \\
\text { value }\end{array}$ & $\begin{array}{l}\text { Residential } \\
\text { Location } \\
\text { Housing } \\
\text { units }\end{array}$ & $\begin{array}{l}\text { Median } \\
\text { Household } \\
\text { income in } \\
\text { dollars }\end{array}$ & $\begin{array}{ll}\text { Average } & \\
\text { commute } & \text { to } \\
\text { work } & \text { in } \\
\text { minutes } & \end{array}$ \\
\hline $\begin{array}{l}\text { Aggregate number of } \\
\text { vehicles available }\end{array}$ & 1 & -0.065 & 0.693 & 0.768 & 0.559 & 0.183 & 0.634 & 0.145 & -0.07 \\
\hline Vehicles available (0) & -0.065 & 1 & 0.389 & -0.085 & -0.450 & -0.144 & 0.563 & -0.796 & -0.057 \\
\hline Vehicles available (1) & 0.693 & 0.389 & 1 & 0.405 & 0.039 & -0.324 & 0.911 & -0.354 & -0.046 \\
\hline Vehicles available (2) & 0.768 & -0.085 & 0.405 & 1 & 0.105 & 0.402 & 0.512 & 0.183 & 0.283 \\
\hline $\begin{array}{l}\text { Vehicles available ( } 3 \\
\text { or more) }\end{array}$ & 0.559 & -0.450 & 0.039 & 0.105 & 1 & 0.271 & -0.129 & 0.480 & -0.369 \\
\hline Median house value & 0.183 & -0.144 & -0.324 & 0.402 & 0.271 & 1 & -0.221 & 0.394 & -0.176 \\
\hline $\begin{array}{l}\text { Residential Location } \\
\text { Housing units }\end{array}$ & 0.634 & 0.563 & 0.911 & 0.512 & -0.129 & -0.221 & 1 & -0.522 & 0.102 \\
\hline $\begin{array}{l}\text { Median Household } \\
\text { income in dollars }\end{array}$ & 0.145 & -0.796 & -0.354 & 0.183 & 0.480 & 0.394 & -0.522 & 1 & 0.169 \\
\hline $\begin{array}{l}\text { Average commute to } \\
\text { work in minutes }\end{array}$ & -0.070 & -0.057 & -0.046 & 0.283 & -0.369 & -0.176 & 0.102 & 0.169 & 1 \\
\hline
\end{tabular}


Very much like Table 3, table 4 illustrates the relationship between car ownership, house value, residential location, household income and commute time within the study's sample for the 2010 period. In this matrix there are minimal changes in the relationships between said variables since 2000. The average commute, however, in 2010 is predominantly inversely related to the majority of the selected variables across the sample indicating that increases in these variables resulted in a decrease in the average commute to work or vice versa. The relationship between the aggregate number of vehicles available (car ownership) and residential location remained positive in 2010. Although there still remained a positive relationship between car ownership and residential location the relationship between these variables and the average commute time to work, though positive and inverse, continued to be very weak.

\section{Conclusion}

In the review of several articles the research was able to identify the factors of car ownership, residential location and house value as three important factors that affect accessibility. Car ownership was identified as a factor due to the dominance of the automobile dependency characteristic of numerous metropolitan areas across the United States including the current study area. Car ownership affords commuters with the luxury of more privacy, comfort and flexibility opposed to the potential unreliability of public transportation. Connected to car ownership is the residential location of individuals in relation to the distance from prospective employment opportunities. Residential location can in fact be influenced by the level of car ownership. The urban and suburban changes in land use have seen people opting to live in either the suburbs or the CBD, and commuting for employment in either alternate location.

Employment accessibility is an issue of great concern in urban areas across the United States significantly for employers as well as prospective employees who may or may not reside with suburban areas. In evaluating employment accessibility, the concept of automobile dependency is a relevant factor for the presence of spatial and/or modal mismatch. Spatial mismatch encompasses the economic restructuring in which employment opportunities for lowincome people are located far away from the areas where they live. The modal mismatch is due to the challenges/inabilities faced by individuals in their travels between home and work or place of potential employment. These key terms along with a brief examination of residential location, housing value and car ownership for the Huntsville Metropolitan Region provides the basic directive for this paper. In selecting the factors that could affect the accessibility to employment the author acknowledged that both the spatial and transportation mismatch are both significant in effectively understanding the concept of accessibility especially in heavily automobile dependent and oriented metropolitan areas.

Employment accessibility is influenced by various factors attributed to the economic and social characteristics of the area. In the review of previous studies, the author was able to identify car ownership, house value and residential location as three basic factors that influence employment accessibility. Upon identifying these factors, the authors was tasked with determining whether or not there was a relationship between/among these factors within the study area of the Huntsville metropolitan region. Theoretically the important factors identified in this study were related; however, the results of the statistical analysis indicate that relationship between these factors and employment accessibility was not significant. As a result it can be implied that while these factors are generally important in accessing employment opportunities, that with the study area's transportation being practically solely automobile dependent makes it difficult to adequately assess the relationships between these factors and accessibility to employment within the Huntsville Metropolitan Region with its current transportation system due to the unavailability data to indicate whether or not commuters had a choice in the mode used to commute.

\section{Compliance with ethical standards}

\section{Disclosure of conflict of interest}

The authors declare no conflict of interest

\section{References}

[1] Grengs, J. Job accessibility and the modal mismatch in Detroit. Journal of Transport Geography, 2010: $42-54$.

[2] Cervero, R. Accessible Cities and Regions: A Framework for Sustainable Transport and Urbanism in the 21st Century. August 01, 2005.

[3] Ong, Paul and Miller, Douglas. Spatial and Transportation Mismatch in Los Angeles. UC Berkeley Earlier Faculty Research. Permalink https://escholarship.org/uc/item/1m84h1b7, Publication Date 2003-05-23 
[4] Jackson, Kenneth T. Crabgrass Frontier: The Suburbanization of the United States. New York: Oxford University Press, 1985.

[5] Handy, Susan. Regional Versus Local Accessibility: Implications for Nonwork Travel. UCTC: Transportation Research Record, 1993: 58-66.

[6] Litman, T., and Laube, F. Automobile Dependency and Economic Development. Available online at: http://www.vtpi.org/ecodev.pdf.,2002.

[7] Geurs, Karst T, and Bert van Wee. Accessibility evaluation of land-use and transport strategies: review and research directions. Journal of Transport Geography, 2004: 127-140.

[8] Walter G. Hansen. How Accessibility Shapes Land Use, Journal of the American Institute of Planners, 25:2, 7376, DOI: $10.1080 / 01944365908978307,1959$.

[9] Cervero, R. and Radisch, C. Travel choices in pedestrian versus automobile oriented neighborhoods. Transport Policy, Volume 3, Issue 3, July 1996, pp 127-141.

[10] Breube, A, E Kneebone, R Puentes, and A Tomer. Missed Opportunity: Transit and Jobs in Metropolitan American. Brookings Institute, 2011.

[11] Yi, Chang. Role of Transportation in Employment Outcomes of the Disadvantaged. PhD Dissertation, Austin, 2009.

[12] Gordon, P, A Kumar, and H Richardson. The Influence of Metropolitan Spatial Structure on Commuting Time. Journal of Urban Economics, 1989: 138-151.

[13] Jackson, Jerry R. Intraurban Variation in the Price of Housing." Journal of Urban Economics, 1979: 464-479.

[14] Fran, Yingling. The Planner's War Against Spatial Mismatch: Lessons Learned and Ways Forward. Journal of Planning Literature, 2012: 153-169.

[15] Daniel Baldwin Hess and Paul M. Ong Traditional Neighborhoods and Automobile Ownership. Transportation Research Record Journal of the Transportation Research Board 1805(1):35-44, January 2002.

[16] Brumback, Elijah. "Mobility Matters: Urban areas defined by accessibility of places, transportation planning." MiBiz. April 14, 2013. http://mibiz.com/news/real-estate/item/20553-mobility-matters-urban-areasdefined-by-accessibility-of-places-transportation-planning.

[17] Freemark, Yonah. HUD and DOT Announce Joint Sustainable Communities Initiative. March $18,2009$. http://www.thetransportpolitic.com/2009/03/18/hud-and-dot-announce-joint-sustainable-communitiesinitiative/ (accessed September 24, 2014).

[18] Stegman, M. "Accessibility Models and Residential Location." Journal of American Institute of Planners, 1969: 22-29. 